Birds of New Guinea

By Tom Iredale. Illustrated with Thirty-Five Plates in Colour, figuring 347 Birds, by Lilian Medland. Vol. 1: Pp. $\mathrm{xv}+230+$ plates $1-15$ Vol. 2: Pp. $x v+261+$ plates 16-35. Edition limited to 1,500 copies. (An Australiana Society Publication.) (Melbourne: Georgian House, Pty., Ltd., 1956.) 24 guineas the set.

THE great tropical island of New Guinea is remarkable for its ecological diversity. The coral coastlines support a lush strand vegetation that gives way to thick rain forests or occasionally (in the south) to savannah. There are great tracts of upland kunai grass-lands, and above these there are mossforests. Over all tower the New Guinea Alps with their cover of permanent snow. There are, too, large rivers and extensive tracts of mangroves, as well as freshwater sago swamps, wide reed-beds and both coastal and upland lakes. These varied conditions support an extraordinary variety of birds and, in particular, great numbers of parrots, pigeons, kingfishers, cassowaries, megapodes ('incubatorbirds'), honey-eaters, bower-birds, birds-of-paradise and other groups that reach their highest development on, or are restricted to, the Australian side of Wallace's Line.

There still remain large areas of New Guinea unvisited by Europeans, although the birds of many relatively accessible districts are rapidly becoming known. Until the appearance of Mr. Iredale's volumes, there was no single, comparatively nontechnical, account of the country's avifauna as, a whole. Mr. Iredale deals with some 650 species, of which 347 are presented in thirty-five beautiful colour-plates. One volume deals with non-passerine forms, and the other with passerines. The work contains a great deal of absorbing information; and it is unfortunate that it gives only the briefest references to other literature. It will be read with critical interest by systematists concerned with the Australasian region, and should be of high general value (and in particular a useful species identification) for New Guinea Europeans with a feeling for natural history. The production maintains the high technical standards of Georgian House. It is sad that the artist, Lilian Medland (Mrs. Iredale), did not live to see the publication of her exquisite pictures.

$$
\text { A. J. Marshati, }
$$

\section{An Introduction to Blood Group Serology}

Theory, Techniques, Practical Applications, Apparatus. By Kathleen E. Boorman and Dr. Barbara E. Dodd. Pp. viii +317. (London : J. and A. Churchill, Ltd., 1957.) 40s, net.

TN 1940, blood grouping meant typing an individual's blood for ABO groups and perhaps occasionally titrating his serum for the corresponding anti-A and anti-B antibody. The other blood groups known at that time were the $\mathbf{M}, \mathbf{N}$ and $\mathrm{P}$ groups, previously discovered by Landsteiner and Levine, and these tests were carried out in cases of disputed parentage. In 1940, Landsteiner and Wiener discovered the $\mathrm{Rh}$ group, and from then on a great change took place. A study of the $\mathbf{R h}$ group showed it to be a complex group that was of considerable clinical significance apart from its importance in blood transfusion therapy, and despite war-time difficulties considerable progress was made in this study both in Britain and the United States during the years following 1940. Additional blood groups have now been discovered so that nine such systems are known. They have been found to be much more complex than was originally thought, and several blood group antibodies recently discovered have detected antigens which are related to one of the previously known blood group systems.

The term 'blood group' implies that an individual has on his own red cells a particular antigen. These react with the corresponding blood group antibodies, and it is the detection of these antigen-antibody reactions that constitutes blood grouping. Prior to 1940, saline agglutination techniques were used, but since 1940 many new techniques have been employed, and but for these the discovery of several blood groups could not have been made and the presence of the corresponding antibody in an individual's serum not suspected. These techniques constitute blood group serology, and it is with these practical matters that this book deals. It describes a large number of methods which are available for this work ; the techniques are numbered and many different ones are described, including those recently introduced into general routine work. It is a pity, however, that the authors do not come down more strongly in favour of particular techniques; a large number is available and it is necessary to choose the most desirable in the given circumstances. Nevertheless, the book forms a handy reference book and guide to laboratory methods, which are succinctly described, and it is well suited for the use of laboratory technicians.

F. Strratton

\section{Semiconductor Surface Physics}

Proceedings of the Conference on the Physics of Semiconductor Surfaces, held at Philadelphia, Pennsylvania, June 4-6, 1956. Edited by R. H. Kingston, with the assistance of E. Burstein, A. L. McWhorter, P. H. Miller, Jr., D. T. Stevenson, and P. B. Weisz. Pp. xvi +413. (Philadelphia : University of Pennsylvania Press ; London: Oxford University Press, 1957.) $63 s$. net.

7 HE papers read at the Conference on the Physics 1 of Semiconductor Surfaces have been divided, in the book, into four groups: $(\alpha)$ clean surfaces; (b) real surfaces; (c) adsorption and catalysis ; (d) oxidation. The second group, not surprisingly, occupies as much space as the others put together; the third, mainly devoted to catalysis, is as much chemistry as it is physics.

It is only very recently that surfaces have been obtained sufficiently free of foreign atoms as to warrant the description 'clean', and further examination of their properties is necessary before existing theories can be checked. The real surfaces of germanium have long been studied, particularly in terms of rates of recombination of holes and electrons (or surface recombination velocity), surface conductances, contact potential and photo effects. Models of the surface, of both germanium and silicon, include 'fast' states, sited at the interface between an oxide layer and the bulk material and responsible for capture times of less than 1 usec., and 'slow' states. The 'slow' states are probably sited on the surface of the oxide layer, have properties which are very dependent on surface treatment and the ambient atmosphere, have long capture times and are responsible for excess noise with an energy spectrum inversely proportional to frequency. The last of the four sections of the book is introduced by a summary of the oxidation of metals and includes a description of experiments on 